\section{DIREITO DE ACESSO À INFORMAÇÃO: uma análise a partir das realidades espanhola e brasileira'}

\author{
João Carlos Gardini Santos* \\ Juan Carlos Fernández Molina* \\ José Augusto Chaves Guimarães
}

RESUMO: A questão do acesso à informação vem impactando significativamente a Ciência da Informação, em especial nos arquivos, como forma de garantia da cidadania. No caso do Brasil e da Espanha, países com larga tradição de colaboração, tem-se leis que garantem o direito de acesso à informação pública, ainda que se verifiquem divergências quanto a sua natureza jurídica. Desse modo, objetivou-se identificar e analisar comparativamente como essa questão é tratada na legislação e na doutrina jurídica desses países. Partindo de uma revisão de literatura, procedeu-se à análise de conteúdo de Bardin nas categorias temáticas: objeto, âmbito de aplicação, publicidade, definições, limites, procedimento, recursos, responsabilidades, fiscalização e taxação. Os resultados revelaram que a legislação brasileira é mais específica e detalhada que a espanhola nas questões conceituais (definição, objeto e procedimentos) e a questão dos limites é mais ampla na Espanha, com menção ao meio ambiente. Essa questão está mais formalizada na Espanha, com o Consejo de Transparencia y Buen Gobierno, ao passo que no Brasil cabe à Controladoria Geral da União, em âmbito federal, e genericamente à "autoridade de fiscalização e monitoramento", em outros âmbitos.

Palavras-chave: Lei de Acesso à Informação. Transparência Administrativa. Organização da informação. Análise de conteúdo.

\footnotetext{
* Advogado e graduando em Biblioteconomia na Faculdade de Filosofia e Ciências da Universidade Estadual Paulista Júlio de Mesquita Filho, Brasil. E-mail: jcgardini@gmail.com.

* Doutor em Documentación, Licenciado en Derecho y Diplomado en Biblioteconomía y Documentación. Catedrático del Departamento de Información y Comunicación de la Universidad de Granada, Espanha.

E-mail: jcfernan@ugr.es.

**** Doutor em Ciências da Comunicação pela Universidade de São Paulo, Brasil. Professor Titular da Universidade Estadual Paulista Júlio de Mesquita Filho, Brasil.

E-mail: guima@marilia.unesp.br.
}

\section{INTRODUÇÃO}

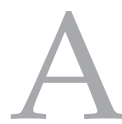

origem do direito de acesso à informação remonta à Ordenança Real sobre Liberdade de Imprensa de 1766, da Suécia, que previa o direito de os cidadãos acessarem a documentação oficial produzida pelo Estado. Mas foi com a Declaração dos Direitos do Homem e do Cidadão, de 1789, da França, que

I Pesquisa financiada pela Fundação de Amparo à Pesquisa do Estado de São Paulo (FAPESP). os cidadãos passaram a ter direito à prestação de contas efetuada pelo Estado sobre a gestão pública, como decorrência implícita do dever da Administração Pública de prestar contas de suas atividades. Mais recentemente, a Declaração Universal dos Direitos Humanos, de 1948, em seu artigo 19, consagrou, aos cidadãos, o direito “[...] de investigar e receber informações e opiniões, e o de difundi-las, sem limitações de fronteiras, por qualquer meio de expressão" (ORGANIZAÇÃO DAS NAÇÕES UNIDAS, 1948). Tem-se, pois, 
o direito de acesso à informação pública como decorrência do direito de informação e liberdade de expressão em geral.

Em 1966, foi aprovado, nos Estados Unidos, o Freedom of Information Act (Lei da Liberdade de Informação) que passou a garantir o acesso a grande parte dos documentos oficiais produzidos pelo Estado. Na América Latina, a Colômbia foi o primeiro país a garantir legalmente o acesso aos documentos oficiais, em 1988 e, em 2002, o México criou uma lei que previa mecanismos ágeis de acesso, supervisionados por órgãos independentestornando-se referência nesse tipo de legislação (GIL-LEIVA; MARTÍNEZ, 2011).

Mais recentemente, o Brasil e a Espanha, em 2011 e 2013 respectivamente, e muitos anos após a promulgação de suas Constituições (de 1988 e de 1978, respectivamente), criaram leis que garantem o direito de acesso à informação pública. Na Espanha aprovou-se a Ley de Transparencia, Acceso a la Información Pública y Buen Gobierno (Lei no 19/2013 - LTAIP) e, no Brasil, a Lei de Acesso à Informação (Lei n ${ }^{\circ}$ 12.527/2011 - LAI).

Ambas as leis trazem impacto direto à Ciência da Informação, principalmente no que tange aos arquivos, na medida em que levam os profissionais da área a refletirem sobre seu dever de garantir o acesso à informação pública e de que modo esse acesso deve ocorrer para que a apropriação da informação seja eficaz para satisfazer as necessidades informacionais dos usuários. No entanto, a aplicação dessas leis vai além, pois a existência de uma verdadeira democracia pressupõe a efetividade do direito dos cidadãos de acessarem todas as informações públicas produzidas pelo Estado e pelos entes que exerçam atividades delegadas a fim de fiscalizar e controlar os gastos das verbas públicas para que casos de corrupção possam ser evitados (MOLINA, 2015). Porém, essa atividade cidadã só é possível a partir da existência de dois institutos jurídicos de vital importância nas sociedades democráticas modernas: a transparência e o direito de acesso à informação pública.

O princípio da transparência é um meio de garantir ao cidadão maior participação no processo decisório estatal, permitindo maior legitimidade, eficácia e responsabilidade da Administração perante os administrados, a fim de que a democracia e o respeito aos direitos fundamentais sejam fortalecidos. A transparência exige que todas as informações relativas às atividades exercidas pelo Estado estejam acessíveis e que o secreto seja a exceção. Daí decorre o direito de acesso à informação, que, em uma perspectiva proativa, consiste na obrigação de os órgãos públicos fornecerem, publicarem e divulgarem as informações referentes às suas atividades para que os cidadãos possam exercer o controle sobre as atividades estatais; já em uma perspectiva, reativa, reside no direito inerente aos cidadãos de solicitar perante o Estado documentos e informações públicas que versem sobre suas atividades.

Tem-se, assim, o direito de acesso à informação como o direito democrático de os cidadãos obterem todos os tipos de informações que estão sob a tutela do Estado e demais entes responsáveis e que não se enquadrem nas hipóteses de sigilo legal. Cabe, assim, ao Estado, criar mecanismos que facilitem a identificação e o acesso à informação desejada pelo cidadão (CAFFERATA, 2009).

Entendido, no Brasil, como um direito fundamental (NOVELINO, 2011), em consequência do exercício da cidadania, o acesso à informação coaduna-se com o artigo 19 da Declaração Universal dos Direitos Humanos, anteriormente citada. Já na Espanha, a doutrina diverge sobre a natureza jurídica do direito de acesso à informação pública, se um direito fundamental ou um direito subjetivo que serve para guiar o Estado no momento de criar políticas públicas (VILLANUEVA CUEVAS, 1993; TORREBLANCA LÓPEZ, 2002; MARTOS, 2016).

Desse modo, necessária se torna uma análise comparativa de como a questão do acesso à informação vem ocorrendo em ambos os países, por meio da análise, seja de suas respectivas Leis de Acesso à Informação seja de sua literatura científica em Ciência da Informação, aspectos que são objeto do presente artigo. Esse tema revela especial interesse para a Ciência da Informação na atualidade uma vez que as questões de produção, organização, recuperação e uso da informação, deparam-se cada vez mais com a questão do direito do cidadão ao acesso à informação pública (bases para que isso ocorra e garantias que possam ser a ele conferidas).

Considerando a estreita dialogicidade entre Brasil e Espanha nas questões informacionais, 
busca-se analisar mais especificamente como ambos os países vêm encarando a questão da transparência administrativa e em que medida suas experiências podem nutrir-se reciprocamente. Para tanto, tem-se como objetivo geral identificar e analisar como a questão do acesso à informação é tratada no atual contexto espanhol e brasileiro, de onde decorrem os seguintes objetivos específicos: a) identificar e analisar como se apresenta a questão do acesso à informação pública nos âmbitos legislativo e doutrinário de ambos os países; e b) analisar como se articulam tematicamente ambas as dimensões.

De modo a atingir os objetivos propostos, procedeu-se a uma revisão da literatura científica da matéria a partir das bases de dados da Biblioteca da Faculdade de Direito e da Faculdade de Documentação e Comunicação da Universidade de Granada, bem como o acervo da Faculdade de Direito da Alta Paulista e a Base Referencial de Pesquisa em Ciência da Informação - BRAPCI.

Para a análise do objeto desta pesquisa e consequente aferição dos resultados utilizou-se a metodologia da análise de conteúdo (BARDIN, 2008), composta pelas fases de pré-análise formação do corpus de análise; exploração do material - onde ocorre a categorização do conteúdo; e tratamento dos resultados - em que se realizam as inferências e resultados (GUIMARÃES; SALES, 2010). As categorias de análise foram estabelecidas a partir da leitura e comparação entre dois documentos públicos procedentes de ambos entornos geográficos e políticos de especial relevância no que tange às questões de acesso à informação pública: o Principles on the Right of Access to Information (ORGANIZAÇÃO DOS ESTADOS AMERICANOS, 2008) e o Access to Official Documents (COUNCIL OF EUROPE, 2003) elaborado pelo Council of Europe.

Desse modo, teve-se como categorias de análise: a) Objeto (o porquê da existência da lei, definindo o bem jurídico tutelado - a informação pública); b) Âmbito de aplicação (sujeitos obrigados ao cumprimento da lei); c) Publicidade (deveres e meios pelos quais o Estado dará publicidade das informações que estão sob sua guarda); d) Definições (termos e respectivos conceitos abordados); e) Limites (exceções ao direito de acesso à informação pública); f) Procedimento (formas de acesso à informação pública almejada e casos de necessidade de expressa justificação para tal); g) Recursos (meios legais disponíveis para que o cidadão tenha revisto o seu pedido negado ou parcialmente concedido de acesso à informação pública); h) Responsabilidades (competências dos agentes públicos no tratamento da informação pública, incluindo infrações e sanções advindas de comportamentos ilícitos); i) Fiscalização (previsão de órgão autônomo para verificar a aplicação da lei e impor medidas sancionadoras); e j) Taxação (previsão ou não de gratuidade no acesso à informação pública).

\section{ACESSO À INFORMAÇÃO PÚBLICA NA ESPANHA E NO BRASIL}

O acesso à informação constitui questão atual e prioritária tanto no âmbito brasileiro quanto no âmbito espanhol, uma vez que relaciona diretamente a questão da transparência do Estado com a garantia dos direitos individuais do cidadão. Nesse sentido, analisam-se, a seguir, as realidades espanhola e brasileira a respeito.

\section{I A realidade espanhola}

Com a promulgação da Constituição de 1978 a Espanha passou a garantir, no artigo 105b, o direito de acesso dos cidadãos aos arquivos e registros administrativos públicos, prevendo lei regulamentará o acesso dos cidadãos aos arquivos e registros administrativos, exceto em casos de segurança e defesa nacional, investigação de crimes e que envolvam a intimidade das pessoas.

Após um longo período de silêncio legislativo a respeito, em 1992, o Régimen Jurídico de las Administraciones Públicas y del Procedimiento Administrativo Común (Lei $\mathrm{n}^{\mathrm{o}}$ 30/1992 - RJAPPAC) tratou, na redação original dos artigos 35h e 37, do direito de acesso aos registros e arquivos da Administração Pública pelos cidadãos, além do respectivo procedimento. Tem-se aqui a garantia de acesso dada à pessoa diretamente interessada em expedientes pontuais desenvolvidos pelo Poder Público e não a todo e qualquer tipo de informação pública. Transcorridas mais de 
duas décadas, em 2013, a LTAIP passou de regulamentar o direito de acesso à informação pública previsto no artigo $105 \mathrm{~b}$ da Constituição, inovando o ordenamento jurídico espanhol com o intuito de garantir a eficácia desse direito constitucional.

A LTAIP se fundamentou em três objetivos que devem guiar toda ação política em torno do acesso à informação pública, expressamente previstos em seu preâmbulo: a) ampliar e reforçar a transparência das atividades públicas; b) regulamentar e garantir o acesso à informação relativo àquelas atividades; e c) determinar quais são as obrigações que os agentes públicos têm em relação às questões de acesso e divulgação da informação pública e as consequentes sanções advindas do seu não cumprimento.

A busca pela transparência nas atividades exercidas pelos agentes públicos constitui medida utilizada nas sociedades modernas para determinar os seus graus de democracia, reduzindo as possibilidades de corrupção (GARCÍA, 2014; MOLINA, 2015). Para tanto, o Capítulo I (artigos 2 a 4) se refere ao âmbito subjetivo de aplicação e inclui como sujeitos obrigados ao cumprimento da lei as pessoas jurídicas de direito público com capacidade política: administração geral do Estado, administrações das comunidades autônomas e administração local, as entidades que gerenciam a Seguridade Social, as agências estatais, as entidades de direito público com personalidade jurídica própria, a Casa da sua Majestade o Rei, os partidos políticos, as organizações sociais e sindicais, dentre outras.

O Capítulo II (artigos 5 a 11) aborda o princípio da publicidade ativa, dispondo que todos os sujeitos elencados no Capítulo I deverão, periodicamente e de forma atualizada, publicar as informações cujo conhecimento seja essencial para garantir a transparência das suas atividades.

Por fim, o Capítulo III (artigos 12 a 24) trata do direito de acesso à informação pública, muito trabalhado por organizações não governamentais que prestam serviços de conscientização sobre esse direito, como a Coalición ProAcceso para quem o acesso à informação pública constitui dever das entidades públicas de publicar informações sobre suas atividades e despesas (direito proativo à informação) e direito do cidadão de solicitar e receber informações públicas provenientes dos órgãos públicos (direito reativo à informação).
O Título III da LTAIP (artigos 33 a 40) dispõe sobre a atuação do Consejo de Transparencia y Buen Gobierno, órgão independente de fiscalização e controle para garantir transparência às atividades públicas, fiscalizar o efetivo cumprimento da publicidade das informações públicas, defender o direito de acesso à informação pública e garantir a efetiva execução das disposições referentes ao Buen Gobierno.

No âmbito doutrinário, o direito à informação vem sendo abordado como desdobramento dos direitos de participação, oriundos dos direitos de liberdade. Tem-se, assim, um direito à informação ativa - de o sujeito comunicar, transmitir uma informação - e um direito à informação passiva, relativo ao recebimento de informação pelas pessoas.

Entendendo como informação pública aquela que decorre dos materiais produzidos pela imprensa, pela internet e pela televisão, enquanto manifestações claras do direito à informação, essa doutrina fornece subsídios para o objeto de tutela da LTAIP: o direito dos cidadãos de acessarem informações públicas, garantido pelo constituinte e regulamentado pelo legislador, e não somente por uma mera expectativa de direito (CONDE; TUR AUSINA, 2015; CALLEJÓN, 2015; GUTIÉRREZ, 2015).

A informação pública é definida pelo artigo 13 da LTAIP como sendo "[...] os conteúdos ou documentos, qualquer que seja o seu formato ou suporte, que estejam na posse de algum dos sujeitos mencionados do âmbito de aplicação deste título e que tenham sido produzidos ou adquiridos no exercício de suas funções" (ESPANHA, 2013, tradução nossa). Observase, assim, que o direito de acesso à informação pública recai sobre conteúdos e documentos produzidos pelo Poder Público, ou sob sua tutela, caso em que é indispensável a consulta ao autor do documento, ainda que sua opinião não seja vinculante, cabendo a decisão final às entidades elencadas nos artigos 2 e 3 da LTAIP (YEBRA, 2013).

A gestão da informação pública é elemento fundamental à transparência, razão pela qual se diz que quanto maior a imposição de limites ao princípio da transparência e à sua gestão consciente, menor o nível de democracia de um país. Nesse sentido, a legislação a respeito tornase essencial para que os registros da atuação governamental sejam colocados à disposição dos 
cidadãos, assim como a regulamentação dessa atuação faz com que seja efetivado o direito de acesso à informação pública e a transparência nas atividades do Estado (GIMÉNEZ-CHORNET, 2012).

Se, por um lado, as novas tecnologias de informação e de comunicação multiplicaram, facilitaram e tornaram mais ágil a apropriação de informações públicas, tais mudanças geraram novos conceitos acerca sobre a documentação e a informação no setor público, notadamente em dois aspectos fundamentais: a geração de documentos durante o exercício legal das atividades típicas e atípicas da Administração e a atuação proativa do Estado relativamente à publicidade desses documentos antes que haja solicitação pelos cidadãos. Tais documentos, por sua vez, podem ser disponibilizados na internet, nos arquivos públicos e bibliotecas públicas, sendo que essas instituições poderão dar acesso a tais informações por meio de seus catálogos em linha ou por outra forma que atenda às suas realidades locais.

Tem-se, pois, que a informação passível de ser entendida como pública é aquela produzida pela Administração Pública com propósitos públicos e que pode compreender “[...] documentos políticos, relatórios de órgãos públicos, registros públicos, legislação e outras espécies de normas, informação meteorológica, bases de dados de informação científica, estatísticas e dados, mapas e informação geoespacial" (MENDO et al., 2013, p. 4, tradução nossa). Especial destaque merece a informação ambiental (información medioambiental), muito demandada, principalmente no setor público espanhol, por produzir efeitos diretos na vida do cidadão, e ligada à situação do meio ambiente ou à segurança ou a saúde das pessoas (SIMÓN; AVILÉS; SERRANO, 2013).

Os limites/restrições ao direito de acesso à informação pública (artigo 14, LTAIP), tidos como exceções à regra, necessitam expressa previsão legal, sendo elencados em um rol taxativo, vinculados à tutela de bens públicos ou privados concorrentes, e passíveis da aplicação do critério de proporcionalidade e de prevalência no caso concreto. Nesse caso, aquilata-se em que medida a restrição/limite imposto visa à tutela de um bem jurídico maior, como a segurança nacional, a defesa do Estado, as relações exteriores, o combate aos crimes e infrações administrativas ou disciplinares, a igualdade entre as partes nos processos judiciais, as funções de vigilância, inspeção e controle, os interesses comerciais e econômicos, a economia, o segredo profissional, a propriedade imaterial, os casos que tramitam sob segredo de justiça e a proteção do meio ambiente (MARTOS, 2016).

A doutrina jurídica espanhola destaca as questões relativas à intimidade, à privacidade e à proteção dos dados como motivadoras de limites ao direito de acesso à informação pública por constituírem direitos fundamentais previstos na Carta de Derechos Fundamentales de la Unión, devendo ser delimitado o que seja de foro pessoal e íntimo apto a ser tutelado pela proteção dos dados (GARRIDO, 2014). Nesse sentido, os artigos 15 da LTAIP e 7.3 da Ley Orgánica $n^{o}$ 15/1999 determinam, como regra, que caso a informação solicitada se refira à origem racial, saúde ou orientação sexual, o acesso somente poderá ser concedido mediante autorização expressa da pessoa afetada, exceto se esses dados tiverem se tornado públicos antes da solicitação, situação em que se dispensa o consentimento da pessoa atingida.

Quatro aspectos que devem ser analisados no momento de divulgar a informação que pode estar resguardada pela intimidade, privacidade ou proteção dos dados pessoais: a) a verificação no caso concreto se o dado de caráter pessoal pode ou não ser objeto de publicidade (e, em caso afirmativo, em que condições e em qual suporte tal ocorrerá); b) os princípios da finalidade e legitimidade para requerer a informação; c) a informação da própria pessoa em questão e; d) o direito de defesa da pessoa atingida pela divulgação de seus dados pessoais e a utilização de novas tecnologias que podem, eventualmente, contribuir na proteção do direito à intimidade (MAÑAS, 2014).

Sobre a solicitação de acesso à informação pública, o artigo 17 da lei espanhola prevê que o pedido de acesso - não necessariamente motivado - deverá ser dirigido ao titular de algum dos órgãos elencados nos artigos 2 e 3 e instruído com a qualificação do solicitante, a informação desejada, endereço para contato (preferencialmente eletrônico) e forma como deseja acessar a informação pública. Ao final da tramitação será emitida uma resolução, passível de recurso, com a procedência ou não do pedido, devendo-se notificar o solicitante e terceiros que 
possam ser diretamente afetados pela divulgação (YEBRA, 2013).

O acesso à informação pública pode ser denegado, mediante decisão fundamentada, em pedidos que tenham por objeto informações em elaboração, pendentes de publicação geral, de caráter auxiliar ou de apoio, que necessitam reelaboração, sejam repetitivas, possuam caráter abusivo face à finalidade de transparência da lei, ou quando o pedido de acesso for dirigido a órgão que não detenha a informação (artigo 18, LTAIP).

A doutrina alerta que o acesso aos informes internos (documentos relativos às tomadas de decisões da instituição) pode prejudicar gravemente o órgão, salvo em caso de prevalência de um interesse público maior (SÁNCHEZ-CASCADO; QUIRÓS, 2014).

Ao analisar a LTAIP, o site Access Info Europe - Defending and Promoting the Right of Access to Information in Europe (ACCESS INFO EUROPE, 2016) destaca problemas como a falta de reconhecimento do acesso à informação como um direito fundamental, a exclusão do Poder Judiciário e entidades privadas que gerenciam os serviços públicos, do âmbito subjetivo de aplicação da lei, a não-manifestação da Administração sobre o pedido de acesso entendida como forma de negação do pedido (artigo 20.4), e a nãoindependência do Consejo de Transparencia e Buen Gobierno cujo Presidente é nomeado pelo Ministro de Hacienda y Administraciones Públicas. Por outro lado, destacam-se como pontos positivo o fato de efetivamente permitir o acesso do cidadão às informações públicas, tendo-se implementado medidas de transparência e acesso à informação para possibilitar a fiscalização dos cidadãos sobre as atividades da Administração Pública, reduzindo possibilidades de corrupção e evitando e/ou sanando eventuais erros de registros - e injustiças advindas destas falhas - relativamente às informações de cada cidadão. A isso se alia o fato de LTAIP haver consagrado o dever do Estado de tornar pública as informações que não estejam abrangidas pelas hipóteses de sigilo (informação proativa), medida essencial a uma sociedade democrática que pressupõe o controle do povo sobre as atividades do Governo.

\subsection{A realidade brasileira}

O direito de acesso à informação, essencial para o pleno exercício dos direitos fundamentais, encontra respaldo no ordenamento jurídico constitucional brasileiro pelo menos desde a Constituição de 1967, reiterado na Emenda Constitucional $\mathrm{n}^{\mathrm{o}} 1$ de 1969 e na atual Constituição de 1988. Nesse sentido, o artigo $5^{\circ}$ da atual Constituição Federal, inserido no âmbito dos direitos e garantias fundamentais, apresenta sobre o tema do acesso à informação três incisos: XIV, XXXIII e LXXII.

Nesse dispositivo legal, enquanto o inciso XIV faz a menção genérica ao direito de acesso à informação, o inciso XXXIII caracteriza-se diretamente como um dos fundamentos da LAI, já que aponta taxativamente o dever de transparência do Estado por meio da publicação de dados e quaisquer tipos de informações de interesse particular e coletivo ou geral independentemente de solicitação. Já o inciso LXXII faz referência ao habeas data que visa a assegurar a obtenção de informações sobre o impetrante constantes em bases do Poder Público em geral (habeas data cognitivo) e para a retificação desses dados caso necessário (habeas data retificatório). Destaca-se que, no direito comparado, não existe instituto jurídico similar, sendo uma criação inicialmente doutrinária que depois foi incorporada ao sistema legislativo brasileiro (SILVA, 2007).

No âmbito da legislação ordinária tem-se a LAI, com o objetivo de garantir o direito de acesso à informação por meio das seguintes diretrizes básicas, que norteiam a divisão estrutural da lei: "[...] a publicidade como princípio geral, o sigilo como exceção, a divulgação de informações de interesse público independentemente de solicitação, a cultura da transparência e o controle social da administração pública" (SOARES; JARDIM; HERMONT, 2013, p. 3), além da utilização de sistemas de comunicação viabilizados pela tecnologia da informação.

Sendo assim, no Capítulo I (artigos $1^{\circ}$ a $5^{\circ}$ ) tem-se as disposições gerais sobre o âmbito subjetivo de aplicação e dos objetivos da lei, estabelecendo que ela deve ser observada pelos órgãos da administração pública direta (União, Estados, Distrito Federal e Municípios), além dos Tribunais de Contas, Poder Judiciário e Ministério Público e os órgãos da Administração 
Pública indireta (autarquias, fundações públicas, empresas públicas e sociedades de economia mista e demais órgãos controlados direta ou indiretamente por quaisquer dos entes que compõem a Administração Pública direta).

O Capítulo II (artigos $6^{\circ}$ a $9^{\circ}$ ) dispõe sobre o acesso às informações e à sua divulgação, encontrando-se, no artigo $8^{\circ}$, a questão da transparência ativa enquanto dever do Estado de prestar informações por ele produzidas ou custodiadas, dando-lhes publicidade. Como consequência, o Capítulo III (artigos 10 a 20) aborda o procedimento do acesso às informações, desde o pedido de acesso, que é gratuito, até os recursos impetrados contra a decisão de negativa do pedido que devem ser endereçados à autoridade hierarquicamente superior àquela que negou.

As restrições de acesso são objeto do Capítulo IV (artigos 21 ao 31), que abrange a classificação das informações quanto a procedimentos, graus e prazos de sigilo, reclassificação e desclassificação de informações, proteção e controle das informações sigilosas, cujas circunstância encontram-se previstas no artigo $23^{2}$.

No âmbito das responsabilidades decorrentes da aplicação desses dispositivos temse, no Capítulo V (artigos 32 a 34), a previsão das condutas ilícitas passíveis de punição dos agentes públicos e dos particulares por danos eventualmente causados e, nas Disposições finais e transitórias (Capítulo VI, artigos 35 a 47), a responsabilidade pela fiscalização da lei, pela Controladoria Geral da União - CGU no âmbito do Poder Executivo Federal, e da autoridade de monitoramento da aplicação da lei em cada

2 Art. 23. São consideradas imprescindíveis à segurança da sociedade ou do Estado e, portanto, passíveis de classificação as informações cuja divulgação ou acesso irrestrito possam: I - pôr em risco a defesa e a soberania nacionais ou a integridade do território nacional; II prejudicar ou pôr em risco a condução de negociações ou as relações internacionais do País, ou as que tenham sido fornecidas em caráter sigiloso por outros Estados e organismos internacionais; III - pôr em risco a vida, a segurança ou a saúde da população; IV - oferecer elevado risco à estabilidade financeira, econômica ou monetária do País; V - prejudicar ou causar risco a planos ou operações estratégicos das Forças Armadas; VI - prejudicar ou causar risco a projetos de pesquisa e desenvolvimento científico ou tecnológico, assim como a sistemas, bens, instalações ou áreas de interesse estratégico nacional; VII - pôr em risco a segurança de instituições ou de altas autoridades nacionais ou estrangeiras e seus familiares; ou VIII - comprometer atividades de inteligência, bem como de investigação ou fiscalização em andamento, relacionadas com a prevenção ou repressão de infrações. (BRASIL, 2011) um dos órgãos que compõem a Administração Pública direta e indireta.

A LAI, como explicado na exposição de motivos $n^{\circ} 7 / 2009$ (BRASIL, 2009), foi resultado de ampla e profunda discussão entre representantes dos Ministérios da Casa Civil, da Justiça, das Relações Exteriores, da Defesa, de Segurança Institucional da Presidência da República, da Comunicação Social e do Controle e da Transparência, da Secretaria Especial de Direitos Humanos e da Advocacia Geral da União, e decorre do reconhecimento da necessidade de criação de instrumentos claros e efetivos que possam garantir o acesso à informação pública, atuando como mecanismos de consolidação dos regimes democráticos, uma vez que o acesso à informação pública é indispensável ao exercício da cidadania e um dos mais eficazes instrumentos de transparência e de combate à corrupção.

$\mathrm{O}$ acesso à informação, como direito fundamental, é reconhecido tanto pela Constituição Federal de 1988, como pela doutrina jurídica brasileira (CANELA; NASCIMENTO, 2009; NOVELINO, 2011; SILVA, 2014), de tal modo que sua tutela é indispensável para o exercício dos direitos e liberdades individuais e para a concretização efetiva da democracia. Nesse sentido, a doutrina diferencia a informação no sentido administrativo, enquanto "[...] parecer, geralmente escrito, em que o funcionário ou empregado fala ou opina a respeito de certo fato ou pedido, prestando os esclarecimentos concernentes aos mesmos ou mostrando a procedência ou improcedência deles" (SILVA, 2007, p. 739), da informação no sentido processual, como ato judicial expresso por meio de depoimentos das testemunhas e informantes da justiça a fim de elucidar determinados fatos.

Todavia, esses conceitos divergem em muito daquele apresentado pelo artigo $4^{\circ}$, inciso I, da LAI que conceitua a informação como "[...] dados, processados ou não, que podem ser utilizados para produção e transmissão de conhecimento, contidos em qualquer meio, suporte ou formato" (BRASIL, 2011). Nessa definição, alguns conceitos merecem destaque, por mais diretamente estarem ligados à Ciência da Informação: dados, produção e transmissão de conhecimento, meio, suporte e formato.

Tem-se por dado "[...] algo acontecido, realizado, feito, e que se tornou irrevogável ou 
necessário" (SEMIDÃO, 2014, p. 71), que, ao ser processado, gera informação. Daí decorre a produção de conhecimento enquanto atividade intelectual realizada pelo responsável por manipular os dados, conhecimento esse que se transmite por meio de sua divulgação a terceiros, interessados ou não. Tais aspectos permitem inferir que, no contexto da LAI, somente os dados que podem ser utilizados para a produção e transmissão do conhecimento é que são considerados informação.

Relativamente a meio, suporte e formato, previstos no texto legal, tem-se por meio o "[...] suporte ou material no qual são registrados dados, por exemplo: papel, disquete, disco rígido, CD-ROM, fita magnética" (CUNHA; CAVALCANTI, 2008, p. 242). O suporte, por sua vez, é o "[...] objeto material, ou dispositivo, sobre o qual se encontram representados os dados ou informações; [...] material (ou dispositivo) ativo ou passivo que pode memorizar uma informação e restituí-la quando necessário" (CUNHA; CAVALCANTI, 2008, p. 352). Por fim, formato é a "[...] descrição da representação física das informações, independentemente da sua representação codificada, p. ex.: livro, periódico ou mapa" (CUNHA; CAVALCANTI, 2008, p. 173).

Acerca do destinatário da lei ou o titular do direito, o artigo 10 da LAI refere-se a "qualquer interessado" em vez de "cidadão", aqui entendido que qualquer pessoa física ou jurídica, nacional ou estrangeira, pode apresentar pedido de acesso à informação pública.

$\mathrm{Na}$ perspectiva dialógica anteriormente mencionada, cumpre destacar que o acesso à informação encontra-se previsto no dispositivo legal analisado, mas somente se faz possível desde que se efetive a sua promoção, objeto das competências profissionais de quem atua na área, conforme bem destacam Rocha e Konrad (2013).

\section{ACESSO À INFORMAÇÃO: ANÁLISE COMPARATIVA ENTRE ESPANHA E BRASIL}

Observou-se, em ambas as leis uma convergência inicial na medida em que todas as categorias de análise nelas se encontram previstas, refletindo o resultado de uma trajetória constitucional que remonta a 1978, na Espanha, e 1967, no Brasil.
No que se refere à definição encontramse apresentados nos artigos 13 da LTAIP e no artigo $4^{\circ}$ da LAI. O rol de conceitos apresentados pela lei brasileira é mais amplo e contempla: informação, documento, informação sigilosa, informação pessoal, tratamento da informação, disponibilidade, autenticidade, integridade e primariedade. A lei espanhola, por sua vez, se limita a conceituar informação pública. Considerando que o objeto de ambas as leis é o acesso à informação pública entendemos que a legislação espanhola é mais adequada ao prever somente o seu conceito, de tal modo que interpretações diversas sobre outros termos sejam mais adequadas que a doutrina e a jurisprudência esclareçam.

Quanto ao objeto, a LTAIP prevê a ampliação, reforço e regulamentação das atividades públicas referentes ao direito de acesso à informação pública, além da criação de normas que devem ser cumpridas pelos agentes públicos a fim de que estes objetivos sejam alcançados e quais as sanções advindas do seu não cumprimento. Nesse aspecto, a LTAIP é mais detalhada e esclarecedora que a LAI, que se limita às disposições sobre os procedimentos que devem observar a União, os Estados, o Distrito Federal e os Municípios na garantia do direito constitucional de acesso à informação pública. No entanto, e apesar das diferenças, o objeto de ambas as leis permanece o mesmo: o acesso à informação pública.

O âmbito de aplicação de cada uma das leis analisadas reflete a organização políticoadministrativa em que se insere. Assim, a LTAIP prevê que a Casa da Realeza, o Congresso dos Deputados, o Senado, o Tribunal Constitucional, o Poder Judiciário, o Banco da Espanha, o Conselho de Estado, a Defensoria Pública, o Tribunal de Contas, o Conselho Econômico e Social e as demais instituições autônomas e análogas somente têm o dever de publicidade proativa das informações relativas às atividades desenvolvidas na esfera do Direito Administrativo. Por outro lado, a LAI, no artigo $2^{\circ}$, traz a genérica e imprecisa ressalva "no que couber", que permite discussões sobre o que cabe ou não àquele tema, além de tornar mais suscetível a ocorrência de violações a tais direitos. Sendo assim, resta a dúvida sobre quais dispositivos, no artigo $2^{\circ}$ da LAI, se aplicam " [...] às entidades privadas sem fins lucrativos que 
recebam, para realização de ações de interesse público, recursos públicos" (BRASIL, 2011).

Existe doutrina defendendo que às entidades sem fins lucrativos aplicam-se somente as normas previstas nos incisos I, II e VI do artigo $7^{\circ}$ da LAI, que abordam, respectivamente, a "[...] orientação sobre os procedimentos para a consecução de acesso, bem como sobre o local onde poderá ser encontrada ou obtida a informação almejada", a "[...] informação contida em registros ou documentos, produzidos ou acumulados por seus órgãos ou entidades, recolhidos ou não a arquivos públicos" e a “[...] informação pertinente à administração do patrimônio público, utilização de recursos públicos, licitação, contratos administrativos" (BACELLAR FILHO; SCHIER, 2013).

$\mathrm{Na}$ categoria publicidade ambas as leis abordam o assunto de modo equivalente, em que a regra é o dever de publicidade das informações públicas e a exceção é o sigilo, cujas hipóteses são retratadas pela categoria limites. Nas duas leis encontramos o dever de publicidade proativa das informações públicas (artigo 5.1 da LTAIP e artigo $3^{\circ}$, inciso II da LAI), sendo que a lei espanhola impõe claramente o dever de publicidade ativa nas informações de natureza institucional, organizacional, de planificação, de relevância jurídica, econômica, orçamentária e estatística, de partidos políticos, organizações sindicais, organizações empresariais e entidades privadas que recebam ajudas ou subvenções públicas.

Diferentemente da lei espanhola, que se refere a "limites" de acesso à informação pública, a LAI se refere a "restrições", mesmo em ambas havendo a mesma intenção de tutelar, de forma geral, o sigilo de informações públicas consideradas imprescindíveis à segurança da sociedade ou do Estado. A LTAIP, de modo a efetivamente cumprir a proteção dos direitos fundamentais de terceira geração, inclui em seu rol de proteção a informação pública cuja divulgação seja capaz de causar qualquer tipo de prejuízo para a proteção do meio ambiente, o que inclui a segurança e a saúde das pessoas, aspecto em que a lei brasileira é omissa, mesmo sendo a tutela do meio ambiente, atualmente, uma das maiores preocupações dos governos de diversos países do mundo.

Quanto à constitucionalidade das hipóteses de restrição de acesso, o Tribunal
Constitucional da Espanha considera que nenhum direito constitucional é um direito ilimitado, sendo que no caso concreto deve-se sempre analisar qual direito constitucional deve prevalecer: se o de acesso à informação pública ou se o limite imposto que visa à proteção de um bem jurídico maior (ESPANHA, 1981). Nessa tônica, a LAI, diferentemente da LTAIP, prevê a possibilidade de classificação das informações de acordo com os seus graus de sigilo, de modo a restringir o acesso de acordo com o teor do documento e conteúdo da informação. Com isso tem-se: informação ultrassecreta (acesso restrito por no máximo 25 anos); informação secreta (15 anos); e informação reservada (5 anos).

Em termos de procedimento para a concretização do direito de acesso à informação pública, a LTAIP exige a qualificação do solicitante, o teor da informação solicitada, um endereço para contato e a modalidade pela qual deseja ter acesso à informação pública, devendo o solicitante encaminhar o pedido preferencialmente por via eletrônica, em quaisquer das línguas não oficiais faladas na Espanha. A LAI, por sua vez, prevê a possibilidade de qualquer pessoa interessada apresentar pedido de acesso à informação pública aos órgãos aos quais se aplicam a lei, devendo o pedido conter a qualificação do solicitante e a informação desejada. No caso espanhol, se a divulgação da informação afeta direitos ou interesses de terceiros devidamente identificados, estes terão o prazo de até 15 dias para realizar as alegações e explanações que entendam pertinentes (YEBRA, 2013). Em ambos os casos, dispensa-se a necessidade da motivação da solicitação, ou seja, do porquê se deseja a informação. (SALGADO, 2015).

Sobre a categoria recursos, a LAI não contempla um órgão autônomo para a apreciação dos recursos de negativa de acesso devendo recurso, com prazo de interposição de até 10 dias a contar da ciência da decisão negativa, ser dirigido à autoridade hierarquicamente superior àquela que negou o acesso à informação pública. A LTAIP, por outro lado, prevê a criação de um órgão independente - o Consejo de Transparencia y Buen Gobierno - para análise dos recursos interpostos com a finalidade de, segundo seu artigo 34, de "[...] salvaguardar el ejercicio de derecho de acceso a la información pública [...]" (ESPANHA, 2013). Os recursos encaminhados para sua análise 
deverão ser prévios à impugnação da negativa na via judicial, com prazo para interposição de até um mês a contar do dia seguinte da notificação do ato impugnado (SÁNCHEZ-CASCADO; QUIRÓS, 2014).

A categoria responsabilidades trata das competências dos agentes públicos para o tratamento da informação e das infrações e respectivas sanções que condutas ilícitas possam ensejar. A LTAIP prevê genericamente que os funcionários compreendidos em seu âmbito de aplicação devem dar cumprimento ao ordenamento jurídico e promover o respeito aos direitos humanos fundamentais e às liberdades públicas, prevendo infrações e sanções em matéria de conflito de interesse e em matéria de gestão econômica-orçamentária. Já o artigo 32 da LAI apresenta um rol taxativo de condutas que ensejam responsabilidade do agente público ou militar, tais como a recusa ao fornecimento de informações públicas requeridas de forma legal ou a demora deliberada no fornecimento da informação almejada pelo solicitante. Para tanto, as sanções variam de acordo com a gravidade do caso concreto e podem ir de uma simples advertência ou multa até uma demissão, para pessoas físicas, e suspensão de participar de licitações e impedimento temporário de contratar com o Poder Público, para pessoas jurídicas.

A fiscalização, no caso espanhol, cabe ao Consejo de Transparencia y Buen Gobierno, órgão independente e autônomo, enquanto a LAI, de forma menos específica, prevê, no artigo 40, incisos I e II, que seja designada uma autoridade do órgão a fim de "[...] assegurar o cumprimento das normas relativas ao acesso a informação, de forma eficiente e adequada aos objetivos" e "[...] monitorar a implementação do disposto nesta Lei e apresentar relatórios periódicos sobre o seu cumprimento" (autoridade de fiscalização e monitoramento) (BRASIL, 2011). No âmbito do Poder Executivo Federal, tal atribuição cabe à CGU, além de promover o fomento à cultura da transparência e a conscientização sobre o direito de acesso à informação e publicar informações estatísticas sobre a implementação da Lei de Acesso e preparar o relatório a ser encaminhado anualmente ao Congresso Nacional.

Por fim, no que tange à categoria taxação, ambas as leis preveem $\mathrm{o}$ acesso gratuito à informação pública, salvo quando da necessidade de reprodução de documentos, cujo custo poderá ser cobrado. Apresenta-se, a seguir, uma síntese dessa análise comparativa (Quadro 1):

Quadro 1 - Incidência das categorias na LTAIP e na LAI

\begin{tabular}{|l|l|l|}
\hline \multicolumn{1}{|c|}{ CATEGORIAS } & \multicolumn{1}{|c|}{ LTAIP } & \multicolumn{1}{c|}{ LAI } \\
\hline Objeto & Acesso à informação pública & Acesso à informação pública \\
\hline Âmbito de aplicação & $\begin{array}{l}\text { Órgãos públicos e privados que exercem } \\
\text { atividades com recursos públicos }\end{array}$ & $\begin{array}{l}\text { Órgãos públicos e privados que exercem } \\
\text { atividades com recursos públicos }\end{array}$ \\
\hline Publicidade & $\begin{array}{l}\text { Regra: dever de publicidade } \\
\text { Exceção: sigilo }\end{array}$ & $\begin{array}{l}\text { Regra: dever de publicidade } \\
\text { Exceção: sigilo }\end{array}$ \\
\hline Definições & Informação pública & $\begin{array}{l}\text { Informação, documento, informação } \\
\text { sigilosa, informação pessoal, tratamento da } \\
\text { informação, disponibilidade, autenticidade, } \\
\text { integridade e primariedade }\end{array}$ \\
\hline Limites & $\begin{array}{l}\text { Necessário para a proteção do Estado, da } \\
\text { sociedade e do meio ambiente }\end{array}$ & $\begin{array}{l}\text { Imprescindível para a segurança do Estado e } \\
\text { da sociedade }\end{array}$ \\
\hline Procedimento & Não precisa ser motivado & Não precisa ser motivado \\
\hline Recursos & Conselho de Transparência e Bom Governo & $\begin{array}{l}\text { Autoridade hierarquicamente superior à que } \\
\text { negou o acesso }\end{array}$ \\
\hline Responsabilidades & $\begin{array}{l}\text { Os agentes públicos e equivalentes } \\
\text { devem cumprir todo o ordenamento } \\
\text { jurídico e promover o respeito aos direitos } \\
\text { fundamentais e às liberdades públicas }\end{array}$ & $\begin{array}{l}\text { Condutas ilícitas que caracterizam } \\
\text { responsabilidade do agente público ou } \\
\text { militar }\end{array}$ \\
\hline Fiscalização & Conselho de Transparência e Bom Governo & $\begin{array}{l}\text { Autoridade de fiscalização e monitoramento; } \\
\text { Controladoria Geral da União (no âmbito } \\
\text { do Poder Executivo Federal) }\end{array}$ \\
\hline Taxação & Gratuito & Gratuito \\
\hline
\end{tabular}

Fonte: Elaborado pelos autores. 
Como se pode observar, a legislação brasileira é mais específica e detalhada no que tange à definição de seus objetos, pois vai além da definição genérica espanhola de informação pública, para conceituar institutos como informação, documento, informação sigilosa, informação pessoal, tratamento da informação, disponibilidade, autenticidade, integridade e primariedade. Com relação aos limites, por outro lado, o Brasil se atém a questões de segurança enquanto a Espanha, de forma mais abrangente, refere-se à proteção do Estado, inclusive com menção ao meio ambiente.

Em termos institucionais, vale destacar uma uma preocupação mais específica da Espanha, com o estabelecimento do Conselho de Transparência y Buen Gobierno ao passo, que no tocante à responsabilidade dos agentes públicos, Brasil e Espanha são giuaulmente genéricos e imprecisos, mencionando qualquer desrespeito ao ordenamento jurídico e a direitos fundamentais e liberdades públicas, no primeiro caso, e condutas ilícitas inerentes a tal responsabilidade, no segundo.

\section{CONSIDERAÇÕES FINAIS}

De uma análise comparativa geral entre a LTAIP e a LAI observam-se muitos aspectos convergentes revelando a preocupação efetiva de ambos os países com a tutela do direito de acesso à informação. Pode-se, assim, dizer que a maior vitória obtida tanto pela LTAIP quanto pela LAI, foi a regulamentação das regras constitucionais e a normatização infraconstitucional de ambos países no que tange ao direito de acesso à informação pública.

No caso espanhol, um exemplo a ser destacado reside na instituição do Consejo de Transparencia y Buen Gobierno, resultado de constantes solicitações e discussões dos cidadãos durante o processo de elaboração da lei. No caso brasileiro, por sua vez, evidencia-se uma efetiva preocupação da lei com o aspecto conceitual, no sentido de se definirem distintos temas relativos à matéria, tais como informação, documentação, informação ambiental etc., o que contribui para uma aplicação mais precisa de seus dispositivos.

Se, por um lado, a realidade brasileira é clara no sentido de configurar o aceso à informação como um direito fundamental, na Espanha observa-se ainda uma divergência de natureza entre um direito fundamental e um direito subjetivo que deve reger as políticas sociais e econômicas do Estado.

No que tange à Ciência da Informação, as leis de acesso à informação impactam mais diretamente os arquivos, cuja missão primordial reside na a gestão documental, por meio da produção, organização, uso, avaliação e arquivamento de documentos, possibilitando o acesso à informação pública a partir dos documentos por eles custodiados. Nesse ambiente informacional é possível vislumbrar um cenário em que seja indispensável a garantia do direito de acesso à informação pública, aspecto que impacta diretamente as discussões sobre a ética arquivística.

Por fim, se, por um lado, verificou-se que o tema do acesso à informação pública é inovador para o Direito e sinaliza para acirradas discussões, por outro, ainda merece maior reflexão no âmbito da Ciência da Informação, em especial no que se refere aos aspectos conceituais e às características da informação, aspectos que levam à necessidade de uma ação investigativa interdisciplinar entre Direito e Ciência da Informação, de modo que a informação passe a constituir efetivamente um instituto jurídico e, o direito a seu acesso e as ações para garantila, passem a ser considerados como processos informacionais. 
Artigo recebido em 28/10/2016 e aceito para publicação em I5/03/20I7

\section{THE RIGHT OF ACCESS TO INFORMATION: an analysis from the Spanish and Brazilian realities}

ABSTRACT: The issue of information access has significantly affected Information Science, nowadays, especially in archives, as a way of guaranteeing citizenship. In the case of Brazil and Spain, there are, in both legal systems, laws that guarantee the right of access to public information, although there are divergences regarding its legal nature. In this way, the objective was to identify and analyze comparatively how information access is treated in the current Spanish and Brazilian legislative and doctrinal contexts. To do so, we started with a literature review followed by the identification and application of the following subject categories: object, scope, publicity, definitions, limits, procedure, resources, responsibilities, supervision and taxation, based on the methodology of Bardin's content analysis. The results revealed that the Brazilian's legislation is more specific and detailed than the Spanish's in conceptual issues (definition, object and procedures) while the question of limits is broader in Spain, referring to the protection of the State and with reference to the environment. This concern is more formal in Spain, with the establishment of the Consejo de Transparencia y Buen Gobierno, while in Brazil there is the Controladoria Geral da União, at federal level, in addition to the generic reference to the "supervisory and monitoring authority ".

Keywords: Law of Access to Information. Administrative transparency. Information organization. Content analysis.

\section{REFERÊNCIAS}

ACCESS INFO EUROPE. Defending and promoting the right of access to information in Europe. 2016. Disponível em: <http://www. access-info.org/es/>. Acesso em: 3 mar. 2016.

CONDE, E. A.; AUSINA, R. T. Derecho constitucional. Madrid: Tecnos, 2015.

BACELLAR FILHO, R. F.; SCHIER, A. C. R. Direito à informação e a aplicação da Lei n. 12.527/11 às Organizações Sociais. In: BACELLAR FILHO, R. F.; HACHEM, D. W. (Coord.). Direito Público no Mercosul: intervenção estatal, direitos fundamentais e sustentabilidade. Belo Horizonte: Fórum, 2013.

CALLEJÓN, F. B. Manual de derecho constitucional: derecho y libertades fundamentales, deberes constitucionales y principios rectores, instituciones y órganos constitucionales. 2. ed. Madrid: Tecnos, 2015.

BARDIN, L. Análise de Conteúdo. Lisboa: Edições 70, 2008.
BRASIL. Congresso Nacional (2011). Lei no 12.527 de 18 de novembro de 2011. Regula o acesso a informações previsto no inciso XXXIII do art. 5o, no inciso II do $\S 30$ do art. 37 e no $\S 20$ do art. 216 da Constituição Federal; altera a Lei no 8.112, de 11 de dezembro de 1990; revoga a Lei no 11.111, de 5 de maio de 2005, e dispositivos da Lei no 8.159, de 8 de janeiro de 1991; e dá outras providências. Diário Oficial da União, Poder Executivo, Brasília, DF, 18 nov. 2011a - edição extra. Disponível em <http:/ / www.planalto.gov. br/ccivil_03/_ato2011-2014/2011/lei/112527. htm>. Acesso em: 22 fev. 2016.

BRASIL. Constituição Federal (1967). Constituição da República Federativa do Brasil de 1967. Promulgada em 24 jan. 1967. Brasília, 15 mar. 1967. Disponível em: <http:// www.planalto.gov.br/ccivil_03/Constituicao/ Constituicao67.htm>. Acesso: 28 ago. 2016.

BRASIL. Constituição Federal (1988). Constituição da República Federativa do Brasil. Promulgada em 5 out. 1988. Brasília, DF, Senado Federal, 5 out. 1988. Disponível em: <http:// www.planalto.gov.br/ccivil_03/constituicao/ 
constituicaocompilado.htm>. Acesso em: 26 ago. 2016.

BRASIL. Exposição de Motivos $\mathbf{n}^{0} 000007$ referente à Lei de Acesso à Informação. 2009. Disponível em: <http://www.planalto.gov.br/ ccivil_03/projetos/EXPMOTIV/EMI/2009/7\%20 - \% 20CC \% 20MJ \% 20MRE \% 20MD \% 20AGU \% 20 SEDH \% 20GSI \% 20SECOM \% 20CGU.htm>. Acesso: 14 mar. 2016.

CANELA, G. Acesso à informação e controle social das políticas públicas. Brasília, DF: ANDI; Artigo 19, 2009.

COALICIÓN PROACCESO. Disponível em: <http://www.proacceso.org/\#>. Acesso: 28 fev. 2016.

COUNCIL OF EUROPE. Access to official documents: Recommendation Rec (2002) 2 of the Committee of Ministers and explanatory memorandum. Strasbourg, 2003.

CUNHA, M.B.; CAVALCANTI, C.R.O. Dicionário de Biblioteconomia e Arquivologia. Brasília: Briquet de Lemos, 2008.

CAFFERATA, S. D. El derecho de acceso a la información pública: situación actual y propuestas para una ley. Lecciones y Ensayos, Buenos Aires, n. 86, p. 151-185, 2009.

ESPANHA. Constitución Española (1978). Constitución Española aprobada por Las Cortes en sesiones plenarias del Congreso de los Diputados y del Senado celebradas el 31 de octubre de 1978. Ratificada por el pueblo español en referéndum de 6 de diciembre de 1978. Sancionada por S. M. el Rey ante Las Cortes el 27 de diciembre de 1978. Disponível em: <https://www.boe.es/legislacion/documentos/ ConstitucionCASTELLANO.pdf>. Acesso: $22 \mathrm{fev}$. 2016.

ESPANHA. Cortes Generales. Ley n ${ }^{\circ} 15$ de 14 de dezembro de 1999. Ley Orgánica 15/1999, de 13 de diciembre, de Protección de Datos de Carácter Personal. Boletín Oficial del Estado, Poder Legislativo, Madrid, 14 dez. 1999. Disponível em: <https://www.boe.es/diario_boe/txt. php?id=BOE-A-1999-23750>. Acesso em: 1 mar. 2016.
ESPANHA. Cortes Generales. Ley no 19 de 9 de dezembro de 2013, de transparencia, acceso a la información pública y buen gobierno. Boletín Oficial del Estado, Poder Legislativo, Madrid, 10 dez. 2013. Disponível em: <https:/ / www.boe.es/ boe/dias/2013/12/10/pdfs/BOE-A-2013-12887. pdf>. Acesso: 22 fev. 2016.

ESPANHA. Cortes Generales. Ley n ${ }^{\circ} 30$ de 26 de noviembre de 1992, de Régimen Jurídico de las Administraciones Públicas y del Procedimiento Administrativo Común. Boletín Oficial del Estado, Poder Legislativo, Madrid, 27 nov. 1999. Disponível em <https://www.boe.es/buscar/ act.php?id=BOE-A-1992-26318>. Acesso: 1 mar. 2016.

ESPANHA. Tribunal Constitucional de España. Sentencia 11/1981, de 8 de abril de 1981. Disponível em: <http://www.mpm.mp.br/ referencias-bibliograficas-documento-juridico/>. Acesso: 29 fev. 2016.

GIL-LEIVA, I.; MOYA MARTÍNEZ, G. El acceso a la información pública: estudio de casos de Brasil, España y Portugal. Informação \& Sociedade: Estudos, João Pessoa, v. 21, n. 1, p. 73-89, jan./abr. 2011.

GIMÉNEZ-CHORNET, V. Acceso de los ciudadanos a los documentos como transparencia de la gestión pública. El profesional de la información, España, v. 21, n. 5, p. 504-508, set./ out. 2012.

GUIMARÃES, J.A.C.; SALES, R. Análise Documental: concepções do universo acadêmico brasileiro em Ciência da Informação. DataGramaZero, v. 11, n. 1, fev. 2010.

GUTIÉRREZ, I. G. (Coord). Elementos de derecho constitucional español. Madrid: Marcial Pons, 2015.

CARMONA, C. M. et al. Del acceso a la reutilización, del dato al documento: uns visión conceptual de la información pública. Revista española de Documentación Científica, Madrid, v. 36, n. 3, p. 1-12, jul./set. 2013.

YEBRA, J. M. La transparencia en las Administraciones Públicas: el procedimimento de acceso a la información pública. Barcelona: Bosch, 2013. 
MOLINA, J. M. Por qué la transparencia. Navarra: Thomson Reuters, 2015.

MARTOS, J.A. M. Transparencia y acceso a la información en España. In: SARLET, I. W.; MONTILLA MARTOS, J.A.; RUARO, R.L. (Coord.). Acesso à informação como direito fundamental e dever estatal. Porto Alegre: Livraria do Advogado, 2016. cap. 3.

GARRIDO, E. N. Transparencia y acceso a los documentos versus derecho a la protección de datos de carácter personal em la reciente jurisprudência del TJUE. In: PIÑAR MAÑAS, J.L. (Org.). Transparencia, acceso a la información y protección de datos. Madrid: Reus, 2014. p. 6396.

NOVELINO, M. Direito Constitucional. 5. ed. São Paulo: Método, 2011.

SÁNCHEZ-CASCADO, E. N.; QUIRÓS, C. T. Transparencia y buen gobierno: comentário a la Ley 19/2013, de 9 de diciembre, de Transparencia, Acceso a la Información Pública y Buen Gobierno. Madrid: La Ley, 2014.

ORGANIZAÇÃO DAS NAÇÕES UNIDAS. Declaração Universal dos Direitos Humanos, adotada e proclamada pela resolução 217 A (III) da Assembleia Geral das Nações Unidas em 10 de dezembro de 1948. Brasília: Unesco, 1998. Disponível em: <http://unesdoc.unesco.org/ images/0013/001394/139423por.pdf >. Acesso em: 03 fev. 2016.

ORGANIZAÇÃO DOS ESTADOS AMERICANOS. Principles on the right of access to information. Rio de Janeiro: OEA, 2008. Disponível em: <http://www.oas.org/cji/eng/ CJI-RES_147_LXXIII-O-08_eng.pdf >. Acesso em: 1 mar. 2016.

MAÑAS, J. L. P. Transparencia y protección de datos. Una referencia a la Ley 19/2013, de 9 de diciembre, de transparencia, acceso a la información y buen gobinerno. In: PIÑAR MAÑAS, José Luis (Org.). Transparencia, acceso a la información y protección de datos. Madrid: Reus, 2014. p. 45-62.

RAMOS SIMÓN, L.F.; ARQUERO AVILÉS, R.; COBO SERRANO, S. La información medioambiental en España: recursos y acceso a la información pública, Revista Interamericana de Medilín, v. 36, n. 3, p. 221-234, sep./dic. 2013.

ROCHA, I. M. M.; KONRAD, G.V.R. A conduta do arquivista frente à Lei de Acesso à Informação. Informação Arquivística, Rio de Janeiro, v. 2, n. 2, p. 103-123, jul./dez. 2013.

SALGADO, E.D. Lei de Acesso à Informação (LAI): comentários à Lei $\mathrm{n}^{\circ} 12.527 / 2011$ e ao

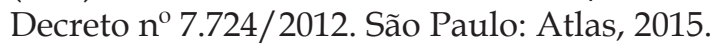

SEMIDÃO, R. A. M. Dados, Informação e Conhecimento enquanto elementos de compreensão do universo conceitual da Ciência da Informação: contribuições teóricas. 2014. 198 f. Dissertação (Mestrado em Ciência da Informação)- FFC-UNESP, 2014.

SENDÍN GARCÍA, M. A. Transparencia y acceso a la información pública. In: RODRIGUEZARANA MUÑOZ, J.; SENDÍN GARCÍA, M.A. Transparencia, acceso a la información y buen gobierno: comentarios a la Ley 19/2013, de 9 de diciembre, de transparencia, acceso a la información pública y buen gobierno. Granada: Comares, 2014.

SILVA, D. P. Vocabulário Jurídico. 27. ed. Rio de Janeiro: Editora Forense, 2007.

SILVA, J. A. Curso de Direito Constitucional Positivo. São Paulo: Malheiros, 2014.

SOARES, F. M.; JARDIM, T.D.M.; HERMONT, T.B.V. Acesso à Informação Pública: uma leitura da Lei ${ }^{\circ}$ 12.527, de 18 de novembro de 2011. Brasília: SEEP/Senado Federal, 2013.

LÓPEZ, A. T. El archivo como servicio público. Boletín de la ANABAD, Espanha, v. 52, n. 3, p. 95-106, 2002.

CUEVAS, A. V. El derecho de acceso a archivos y registros. Revista jurídica de Castilla - La Mancha, Espanha, n. 18, p. 109-132, 1993. 